Check for updates

Cite this: RSC Adv., 2019, 9, 10796

Received 15th January 2019

Accepted 22nd March 2019

DOI: $10.1039 / c 9 r a 00253 g$

rsc.li/rsc-advances

\section{A novel positively charged composite nanofiltration membrane based on polyethyleneimine with a tunable active layer structure developed via interfacial polymerization}

\author{
Zhibin Jiang, ${ }^{\text {abe }}$ Jing Miao, (D) *ac Yuantao He, ${ }^{\text {ab }} \mathrm{Kai}^{\mathrm{Tu}}{ }^{\text {a }}$ Shunquan Chen, ${ }^{\text {a }}$ \\ Rui Zhang, ${ }^{* c}$ Ling Zhang (D) ${ }^{* d}$ and Hao Yang (D) $* b$
}

A novel positively charged composite nanofiltration (NF) membrane with tunable active layer structure was successfully developed via interfacial polymerization on a polysulfone (PSF) ultrafiltration (UF) membrane surface, using polyethyleneimine (PEI) as the monomer of the aqueous phase, and a mixture of isophthaloyl dichloride (IPC) and tri-mesoyl chloride (TMC) as the monomer of the organic phase. Interestingly, a synergetic effect of the mass ratio of IPC and TMC was observed on the pore size and the structure of the active layer of the resultant polyamide (PA)/polysulfone (PSF) composite NF membrane. The rejection $(R)$ to the inorganic electrolytes increased with the mass ratio of IPC to TMC, while the permeate flux $(F)$ escalated up to a 1:1 mixing ratio of IPC to TMC and dropped at higher mixing ratios. The rejection to different inorganic electrolytes decreased in the order of $\mathrm{ZnCl}_{2}, \mathrm{MgCl}_{2}$, $\mathrm{CaCl}_{2}, \mathrm{CuCl}_{2}, \mathrm{MgSO}_{4}, \mathrm{NaCl}$, and $\mathrm{Na}_{2} \mathrm{SO}_{4}$. At ambient temperature and $0.4 \mathrm{MPa}$, the optimized membrane demonstrated $R$ and $F$ to $1 \mathrm{~g} \mathrm{~L}^{-1} \mathrm{MgCl}_{2}$ aqueous solution as $98.1 \%$ and $27.6 \mathrm{~L} \mathrm{~m}^{-2} \mathrm{~h}^{-1}$, respectively. Its rejection to various dyes reduced significantly in the order of cationic red X-GTL (100\%), rhodamine B (94.2\%), cationic gold yellow X-GL (93.5\%), and brilliant blue KN-R (43.9\%), in agreement with the decrease in the molecular weight $\left(M_{w}\right)$ and the overall charges of the dye.

\section{Introduction}

Membrane separation technology is the most economic approach among the seawater desalination technologies. Nanofiltration (NF) is a pretreatment technology for the reverse osmosis (RO) seawater desalination process, which effectively removes most di-/multi-valent ions $\left(\mathrm{Mg}^{2+}, \mathrm{Ca}^{2+}\right.$, and $\mathrm{SO}_{4}{ }^{2-}$, etc. $)$ from seawater as well as some monovalent ions $\left(\mathrm{Na}^{+}, \mathrm{K}^{+}\right.$, and $\mathrm{Cl}^{-}$, etc.), and hence reduces the operating pressure of the $\mathrm{RO}$ process. ${ }^{1-4}$ In addition to its use in pretreatment for seawater desalination, NF is also widely utilized in applications such as

${ }^{a}$ Guangdong Key Laboratory of Membrane Materials and Membrane Separation, Guangzhou Institute of Advanced Technology, Chinese Academy of Sciences (CAS), Guangzhou 511458, PR China. E-mail: jing.miao@giat.ac.cn; jmiao@jinzhenghb. com; Fax: +86-2022912525; Tel: +86-13829708450

${ }^{b}$ Key Laboratory for Green Chemical Process of Ministry of Education, School of Environmental Ecology and Biological Engineering, Wuhan Institute of Technology, Wuhan, 430205, PR China. E-mail: hyang@wit.edu.cn

'Shandong Disk Tube Reverse Osmosis (DTRO) Membrane Engineering Laboratory, The New Water Technology, Inc. (NEWA), China.E-mail: niureal@gmail.com

${ }^{d}$ School of Resource and Environment, University of Jinan, Jinan 250022, PR China. E-mail: chm_zhangl@ujn.edu.cn

${ }^{e}$ School of Chemistry and Environment, South China Normal University, Guangzhou 510631, China wastewater treatment, water purification, water softening, concentration and separation of active intermediates, etc. $^{5-9}$

Most of the currently available commercial NF membranes are negatively charged composite NF membranes for desalination, ${ }^{10}$ ionic exchange, ${ }^{11}$ dye purification, ${ }^{12}$ toluidine blue $\mathrm{O}$ separation, ${ }^{13}$ osmotic power generation from municipal wastewater, ${ }^{14}$ removal of typical pharmaceutical molecules, ${ }^{15}$ etc. As the NF technology has found vast applications in various industries, the demand for novel positively charged composite NF membranes has grown tremendously.

Interfacial polymerization (IP) on an ultrafiltration (UF) membrane at ambient temperature has been employed extensively in the fabrication of positively charged composite NF membranes due to its ease of operation, flexibility, effectiveness, and economical efficiency. ${ }^{\mathbf{1 6 , 1 7}}$ The IP process occurs at the interface between the aqueous phase and the organic phase, as the water-soluble monomer comes into contact with the organic monomer. ${ }^{18,19}$ Most of the commercial NF membranes are PA composite NF membranes, fabricated using amine and acyl chloride as the aqueous monomer and the organic monomer, respectively. The rejection performances of the NF membrane were tuned by the types of monomer, the preparation method, the post heat treatment, the molecular weight cut-off (MWCO) of the base membrane, etc. ${ }^{\mathbf{2 0}-23}$ In order to improve the rejection 
performance, anti-oxidization and antifouling properties, numerous studies have been focused on employing novel monomers, adding surfactants and additives to the aqueous or organic phase, and the conditions of post heat treatment, etc. ${ }^{18,24-26}$

Due to rich active amine groups in the polymer chains, polyethyleneimine (PEI) has been widely employed to prepare the positively charged composite NF membranes. The resultant PEI composite NF membranes showed high ion selectivity and rejection to positively charged solutes.

Several literatures reported fabrication, characterizations, and rejection performance of the positively charged composite $\mathrm{NF}$ membranes prepared via IP, using PEI as the monomer in the aqueous phase. Chiang, ${ }^{27}$ Sun, ${ }^{28}$ and Thong, ${ }^{29}$ et al. have investigated the impact of the chemical structure of the di- $/$ multi-amine on the performance of the resultant composite NF membrane. It was found that the increase in the charged group in the resultant composite NF membranes could enhance the rejection to inorganic electrolytes and does not affect the permeate flux. The rejection also increased with the molecular weight $\left(M_{\mathrm{w}}\right)$ of PEI due to the decrease in the membrane pore size, while the permeate flux decreased. The above observation is contrary to the results by Thong et al. Furthermore, Gao ${ }^{30}$ and Lee, et $a l .^{31}$ investigated the influence of the acyl chloride on the rejection performance of the resultant composite NF membrane. In the work done by Lee, et al., a novel pH-stable composite NF membrane was prepared with interfacial polymerization, using PEI and cyanuric chloride (CC) as the monomers in the aqueous and organic phases, respectively. The resultant composite NF membrane could be stable at extreme $\mathrm{pHs}$, because the functional groups were able to resist the attacks by the nucleophilic and electrophilic reagents. In another word, rejection performance, including the rejection $(R)$, the permeate flux $(F)$, and the MWCO, was maintained with the resultant composite NF membranes immersed in $\mathrm{HNO}_{3}$ and $\mathrm{NaOH}$ aqueous solutions at $\mathrm{pH} 1$ and $\mathrm{pH} 13$, respectively, for more than one month. Moreover, a novel antifouling PEI-based thin film composite (TFC) NF membrane was developed via an in situ manipulation approach, using dextran (Dex) conjugate of PEI (PEI-Dex) as a new monomer or co-monomer together with TMC in the interfacial polymerization (IP). ${ }^{32}$ The resultant PEIbased membrane exhibited excellent antifouling properties compared to that of conventional TFC NF membranes based on piperazine and it was suitable for long-term water softening without frequent membrane cleaning.

The low-pressure PEI composite NF membranes with relatively high rejection $(R)$ and permeate fluxes $(F)$ had been developed by adjusting the parameters in preparation process, such as monomer concentration, IP time, the condition of post heat treatment, etc. Molecular assembly is another effective way to optimize the rejection performance of the PEI based composite NF membrane. TFC NF membranes with a layer-bylayer structure formed via IP between PEI and TMC were developed by repeating cycles of sequential reactant depositions and reactions for better salt rejection. The results suggested that the PEI-TMC NF membranes were much more permeable than the TMC-PEI NF membranes, and the proper post heat treatment boosted the salt rejection of the resultant TFC NF membrane..$^{33}$

The research mentioned above has shown vast improvement in the properties of the positively charged PEI composite NF membranes, including rejection, permeate flux, anti-fouling characteristic, and $\mathrm{pH}$ stability, etc. However, the relatively low permeate flux, which directly affects the production efficiency of the membrane, still hinders the wide application of the PEI composite NF membranes in industries. To obtained polyamide-based composite NF hollow fiber membranes with desirable characteristics for water softening at relatively low operating pressure in the ultrafiltration range, Fang, et al. ${ }^{34}$ employed the aqueous phase containing a mixture of PEI and piperazine (PIP) to react with TMC in the organic phase. Synergetic effect of PEI and PIP was found on the formation of the selective layer. Specifically, the resultant membrane demonstrated higher water permeability and salt rejection at a certain PIP to PEI ratio. Therefore, it could be concluded that the ratio of reacting monomers played a critical role on the permeability and the active layer thickness of the resultant polyamide-based membrane.

In this work, a novel positively charged composite NF membrane has been fabricated for the first time via IP between PEI and a mixture of IPC and TMC of various mass ratio. It was the first time that a novel kind of positively charged composite NF membrane has been fabricated with the IP between PEI and the mixture of IPC and TMC with different mass ratio. The resultant membranes were characterized by SEM, AFM, ATRFTIR. Contact angle and zeta potential were employed to determine their hydrophilicity and electrokinetic characteristics, respectively. The investigations were conducted to understand the effect of the mass ratio of IPC to TMC on the rejection performance of the PA/PSF composite NF membrane, rejection of an optimized membrane to different inorganic electrolytes, and how MW and charges affects rejections to dyes of different structures.

It was found that the PA/PSF composite NF membrane with the high rejection rate was more permeable compared with the membranes developed with TMC or IPC alone as the organic phase IP monomer. The composite NF membranes with relatively thinner active layers could be easily obtained via controlling the ratios of IP monomers. This work will provide the base for the development and application of the TFC NF membranes prepared with IP, using PEI as the monomer of the aqueous phase.

\section{Experimental section}

\subsection{Chemicals and materials}

The polysulfone (PSF) ultrafiltration (UF) substrate, with a MWCO of $30 \mathrm{kDa}$, were provided by Pureach Tech Ltd (Beijing, China). Polyethyleneimine (PEI, MW: 70000 Da, 50 wt\%), trimesoyl chloride (TMC, 98.0\%), and isophthaloyl chloride (IPC, 98.0\%) were purchased from Shanghai Macklin Biochemical Co., Ltd., China. $n$-Hexane and all inorganic electrolytes with AR grade, including $\mathrm{ZnCl}_{2}, \mathrm{MgCl}_{2}, \mathrm{CaCl}_{2}, \mathrm{CuCl}_{2}, \mathrm{MgSO}_{4}, \mathrm{NaCl}$, and $\mathrm{Na}_{2} \mathrm{SO}_{4}$, were purchased from SINOPHARM, China. The dyes, 
including cationic red X-GTL, rhodamine B, cationic gold yellow $\mathrm{X}-\mathrm{GL}$, and reactive brilliant blue $\mathrm{KN}-\mathrm{R}$, were obtained from Tianjin Longshengxiang Science and Technology Ltd., China. Fig. 1 shows the molecular structures of different dyes. Milli-Q water was used for the preparation and the permeation tests. All chemicals were used without further purification.

\subsection{Preparation of the positively charged PA/PSF composite NF membranes}

The positively charged polyamide/polysulfone (PA/PSF) composite NF membranes were fabricated via interfacial polymerization (IP). ${ }^{36}$ The preparation process was described as the following. The PSF UF substrates were immersed in $3.7 \mathrm{wt} \%$ PEI aqueous solution for $5 \mathrm{~min}$, and then the excess aqueous solution was removed. The membranes were dried at $30{ }^{\circ} \mathrm{C}$ for $30 \mathrm{~min}$. After drying, the membranes were immersed for $90 \mathrm{~s}$ in $0.25 \mathrm{w} / \mathrm{v} \%$ acyl chloride $n$-hexane solution containing the IPC and TMC mixed at different mass ratio. After IP, the PA/PSF composite NF membranes were rinsed extensively and stored for further uses. Especially, the membrane samples fabricated as the mass ratios of IPC to TMC were $0: 1,1: 1$, and $1: 0$, respectively, were labeled as $\mathrm{PA}_{01} / \mathrm{PSF}, \mathrm{PA}_{11} / \mathrm{PSF}$, and $\mathrm{PA}_{10} / \mathrm{PSF}$, respectively. Fig. 2 shows the structures of PSF, PEI, IPC, TMC molecules, and possible polymer network of PA active layer for PA/PSF composite NF membranes.

\subsection{Characterizations of the resultant TFC NF membranes}

The surface and the cross-section morphologies of PSF UF substrate and the positively charged $\mathrm{PA}_{01} / \mathrm{PSF}, \mathrm{PA}_{11} / \mathrm{PSF}$, and $\mathrm{PA}_{10} / \mathrm{PSF}$ composite NF membranes, were observed with scanning electron microscope (SEM, Phenom XL, Netherlands). Before observation, these samples were fractured in liquid nitrogen, and were sprayed with gold on the surface by using an ion sputter JS-16009. The 3-D morphology and the roughness of the membrane surface were obtained on an atomic force microscope (AFM, SPM-9700, Shimadzu Corp., Japan). The chemical structures of the membranes were investigated by attenuated total reflectance-fourier transform infrared (ATRFTIR) spectroscope (Nicolet iS10, Thermo Fisher Scientific, the United States). Furthermore, the hydrophilicities of the membranes were characterized with a water contact angle (CA) goniometer (Drop Shape Analyzer-DSA30, KRÜSS, Germany). The electro-kinetic characteristic of the membrane surface was characterized with an electrokinetic analyzer (SurPASS ${ }^{\mathrm{TM}} 3$, Anton Paar $\mathrm{GmbH}$, Austria) at $\mathrm{pH}$ ranging from 2 to 10, using $0.001 \mathrm{~mol} \mathrm{~L}^{-1} \mathrm{KCl}$ aqueous solution. The surface zeta potential was calculated according to the Helmholtz-Smoluchowski equation with the Fairbrother and Mastin substitution. ${ }^{37}$

\subsection{Rejection performances}

The rejection performances of the resultant composite NF membranes were evaluated with a cross-flow filtration equipment with an effective membrane area of $70 \mathrm{~cm}^{2}$. The concentrations of the inorganic electrolytes, the dyes, and the PEG with different MW herein are $1.0 \mathrm{~g} \mathrm{~L}^{-1} . R$ and $F$ were calculated with the following equations.

$$
R=\left(1-\frac{c_{\mathrm{p}}}{c_{\mathrm{r}}}\right) \times 100 \%
$$<smiles>CCN(CC[N+](C)(C)C)c1ccc(N=Nc2ccc([N+](=O)[O-])cc2Cl)cc1</smiles>

(a) Cationic red X-GTL<smiles>Cc1cc(Nc2cccc(S(=O)(=O)OCCS(N)(=O)=O)c2)c2c(c1N)CC1=C(C2)C(=O)C=CC1=O</smiles>

(c) Reactive brilliant blue KN-R (b) Rhodamine B<smiles>COc1ccc(N(C)/N=C/C2=[N+](C)c3ccccc3C2(C)C)cc1</smiles>

(d) Cationic gold yellow X-GL

Fig. 1 Chemical structures of different dyes. ${ }^{35}$ 


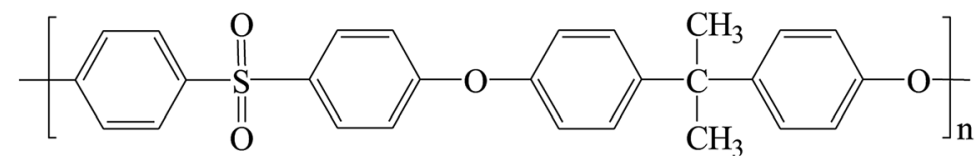

(a)

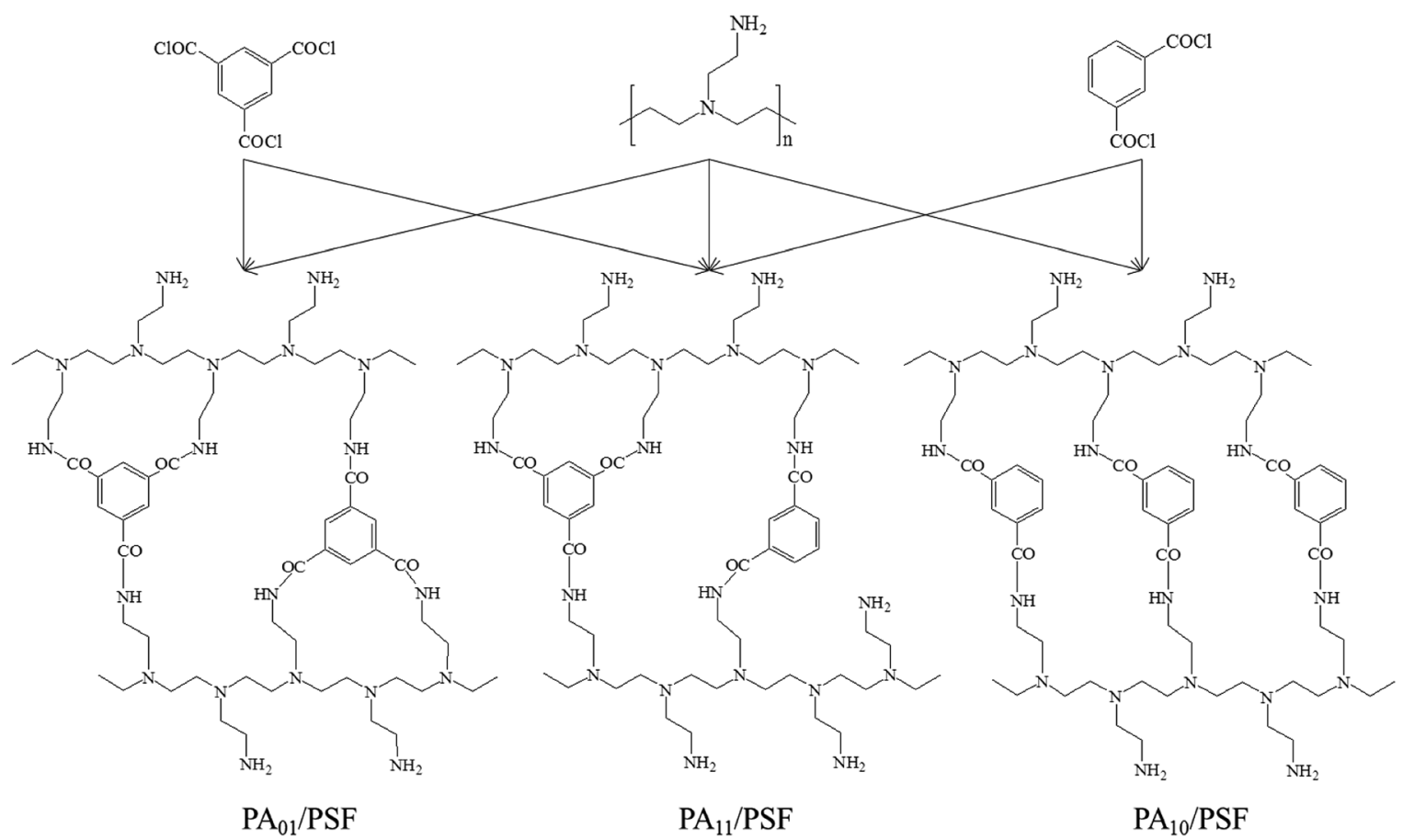

(b)

Fig. 2 Chemical structures of (a) PSF UF substrate and (b) possible network of PA active layer for the positively charged PA/PSF composite NF membranes.

$$
F=\frac{V}{A \times \Delta t}
$$

where, $F$ is permeate flux $\left(\mathrm{L} \mathrm{m}^{-2} \mathrm{~h}^{-1}\right), V$ is volume of permeation fluid (L), $\Delta t$ is permeation time (h), $A$ is effective permeation area $\left(\mathrm{m}^{2}\right), R$ is rejection rate $(\%), c_{\mathrm{p}}$ and $c_{\mathrm{r}}$ are the concentration of the permeation and feed solution $\left(\mathrm{g} \mathrm{L}^{-1}\right)$, respectively. The electrical conductivity was determined with the electrical conductivity meter (DDS-307, Inesa, China) to get the concentration of inorganic electrolyte via the standard curve of electrical conductivity vs. concentration of inorganic electrolyte. The concentrations of the dyes and PEG with different MW were measured and determined with the ultraviolet-visible spectrophotometer (UV-6100, MAPADA, China).

\section{Results and discussions}

\subsection{Characterization of membrane material}

3.1.1. Scanning electron microscopy (SEM). SEM was employed to observe the surface and the cross-section images of (a and b) PSF UF substrate and ( $\mathrm{c}-\mathrm{h}$ ) the positively charged PA/ PSF composite NF membranes in Fig. 3. As shown in Fig. 3(a), (c), (e) and (g), the surface of PSF substrate was smooth and clean, while the active layers of PA/PSF composite NF membranes were heterogeneous and rough. ${ }^{38-43}$ At IPC to TMC mass ratio of $0: 1$ (labelled as $\mathrm{PA}_{01} / \mathrm{PSF}$ ), the surface of $\mathrm{PA}_{01} / \mathrm{PSF}$ membrane was covered with small granules, like PSF UF substrate. As this mass ratio being increased to $1: 1$, the small granules disappeared, the wrinkles showed up in the same pattern of the tiled graphene oxide surface. In addition, the active layer at 1:1 mixing ratio was measured to be thinner than the mixing ratio of $0: 1$, and the surface was coarser, possibly resulting in a higher specific surface area. ${ }^{44}$ The rougher surface and thinner thickness were considered to be beneficial to the water permeability of the membrane because it enlarges the effective area of the membrane surface. ${ }^{45}$ However, the morphology of the membrane surface changed again at the mass ratio of $1: 0$. Twisted particles were detected in Fig. $3(\mathrm{~g})$. The above results strongly suggested that the surface morphology of PA active layer was highly correlated with the structure and the mass ratio of acyl chloride.

As for the cross-section morphologies shown in Fig. 3(b), (d), (f) and (h), it could be observed that each cross section of PA/ PSF composite NF membranes was composed of two distinct layers with one being a spongy supporting layer, and the other 

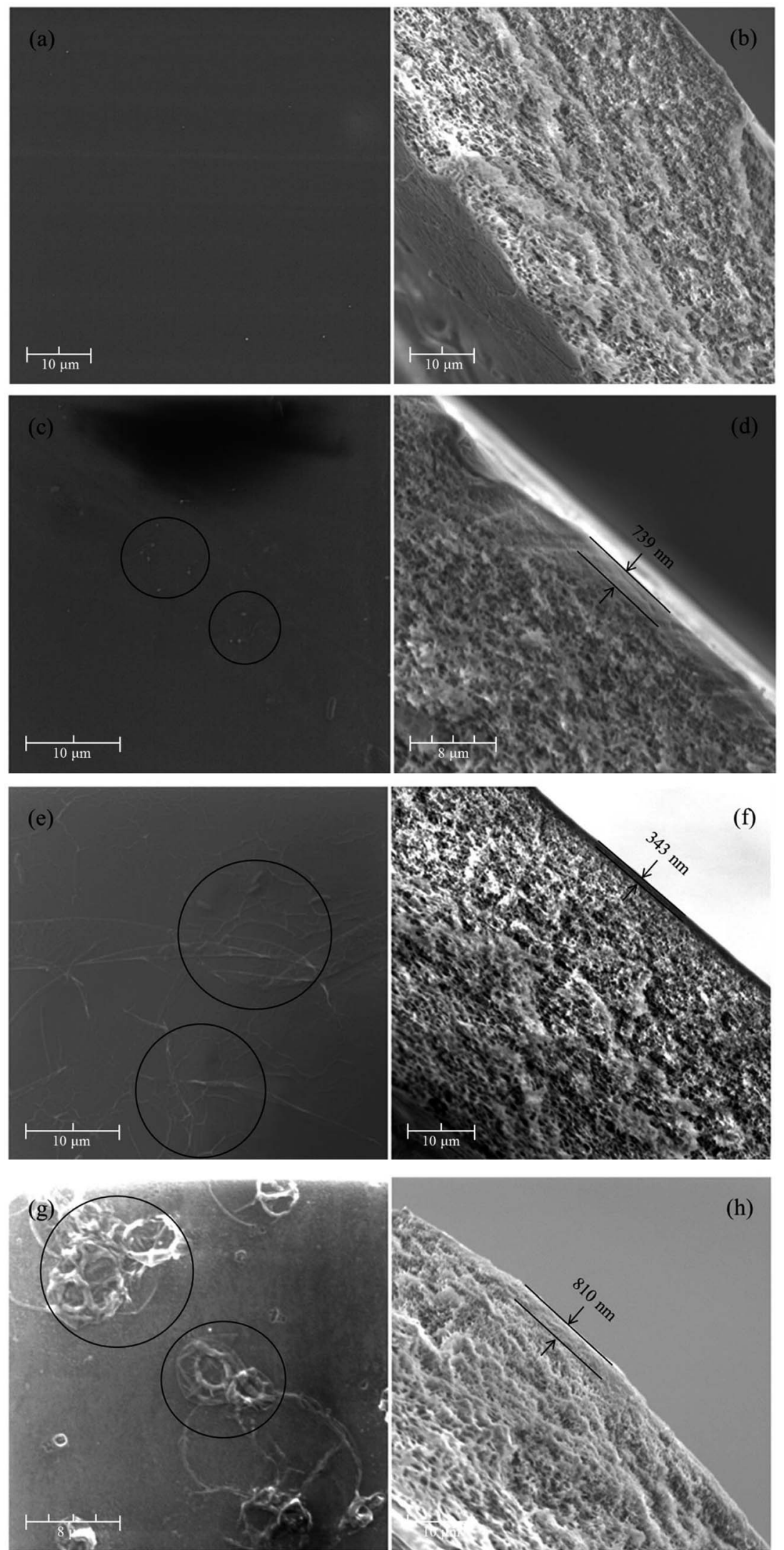

Fig. 3 The surface and cross-section images of ( $a$ and b) PSF UF substrate, (c and d) PA $A_{01} / P S F$, (e and f) PA $11 / P S F$ and ( $g$ and h) PA $A_{10} / P S F$ positively charged TFC NF membranes at 6000× magnification. 
being a tighter and thinner PA active layer. Furthermore, the thickness of $\mathrm{PA}$ active layer for $\mathrm{PA}_{01} / \mathrm{PSF}, \mathrm{PA}_{11} / \mathrm{PSF}$, and $\mathrm{PA}_{10} / \mathrm{PSF}$ composite NF membranes were measured to be $739 \mathrm{~nm}$, $343 \mathrm{~nm}$, and $810 \mathrm{~nm}$, respectively. The above results suggested that the resultant PA composite NF membranes fabricated at $1: 1$ mass ratio of IPC to TMC have the thinnest PA active layer among the three membranes. Similar morphologies have been reported in the literatures. ${ }^{38,41,43,46,47}$

Based on the above results, it could be concluded that a thin functional active layer has been successfully prepared onto the PSF UF substrate via the interfacial polymerization between PEI and a mixture of IPC and TMC. As the total mass of acyl chloride was set at a certain value, the higher mass ratio of IPC to TMC was, the more $-\mathrm{NH}_{2}$ would be remained. This will result in the aggregations of excess PEI molecules on the membrane surface in the form of wrinkles and twisted particles, as observed in Fig. 3(c), (e) and (g). ${ }^{27}$

3.1.2. 3-D morphology and surface roughness of the resultant TFC NF membrane. To further reveal the relationship between the surface morphology and the rejection performance of the resultant PA membrane, the 2-D and 3-D surface morphology of the PSF UF substrate and the resultant PA/PSF positively charged composite NF membranes were also scanned at three different locations and three times at each location by AFM. The average values of the root mean square roughness $\left(R_{\text {rms }}\right)$ were calculated and presented in Table 1 . Fig. 4 shows the analytical results of 2-D and 3-D surface morphologies, in agreement with SEM results. Apparently, some wrinkles and twisted particles could be easily observed in Fig. 4(c) and (d). ${ }^{38,40}$

The $R_{\mathrm{rms}}$ of PSF UF substrate and PA/PSF composite NF membrane were summarized in Table $1 .^{\mathbf{4 0}}$ The commercial PSF UF substrate exhibited a relatively smooth surface with the lowest $R_{\mathrm{rms}}$ of $4.23 \mathrm{~nm}$. After the PA active layer was introduced onto the PSF UF substrate, rough surfaces of wrinkles or twisted particles became visible, and the roughness increased with the mass ratio of IPC to TMC. The $R_{\mathrm{a}}$ of $\mathrm{PA}_{01} / \mathrm{PSF}, \mathrm{PA}_{11} / \mathrm{PSF}$, and $\mathrm{PA}_{10} / \mathrm{PSF}$ composite NF membranes were $4.57 \mathrm{~nm}, 43.90 \mathrm{~nm}$, and $11.83 \mathrm{~nm}$, respectively, as the mass ratio of IPC to TMC changed from $0: 1$ to $1: 0$. Particularly, the one with wrinkled PA active layer, similar to the tiled graphene oxide surface, would have the largest roughness, suggesting that the results measured by AFM agreed with the morphologies obtained from SEM. ${ }^{41}$ Besides, the membrane with the higher roughness corresponded to the higher specific surface area, which benefited the permeate flux. The results suggested that the surface morphology and the roughness of the PA/PSF composite NF membranes were mainly determined by the mass ratio of IPC to

Table $1 \quad R_{\text {rms }}$ of (a) PSF UF substrate, (b) PA $\mathrm{A}_{01} / \mathrm{PSF}$, (c) $\mathrm{PA}_{11} / \mathrm{PSF}$, and (d) $\mathrm{PA}_{10} / \mathrm{PSF}$ positively charged composite NF membrane

\begin{tabular}{lr}
\hline Membrane samples & \multicolumn{1}{c}{$R_{\mathrm{rms} / \mathrm{nm}}$} \\
\hline $\mathrm{PSF}$ & $4.23 \pm 0.09$ \\
$\mathrm{PA}_{01} / \mathrm{PSF}$ & $4.57 \pm 0.06$ \\
$\mathrm{PA}_{11} / \mathrm{PSF}$ & $43.90 \pm 0.05$ \\
$\mathrm{PA}_{10} / \mathrm{PSF}$ & $11.83 \pm 0.07$
\end{tabular}

TMC. The higher mass ratio of IPC to TMC was, the more $-\mathrm{NH}_{2}$ was remained, and the larger particles on the selective layer surface would be.

3.1.3. ATR-FTIR spectra. The ATR-FTIR spectroscopy was used to characterize the chemical structures of composite NF membranes and the spectra of PSF UF substrate, $\mathrm{PA}_{01} / \mathrm{PSF}, \mathrm{PA}_{11} /$ $\mathrm{PSF}$, and $\mathrm{PA}_{10} / \mathrm{PSF}$ composite NF membranes were shown in Fig. 5. Comparing the contrast spectrum of PSF in Fig. 5(a) with those of composite NF membranes in Fig. 5(b-d), a new strong absorbance peak appeared at $1686 \mathrm{~cm}^{-1}$, which could be attributed to the characteristic peak of the $\mathrm{C}=\mathrm{O}$ stretching. ${ }^{38,39,46-49}$ Another new peak with wide and strong absorbance presented at $3400 \mathrm{~cm}^{-1}$ might be attributed to the $\mathrm{N}-\mathrm{H}$ stretching peak in PEI molecule..$^{36,43,49,50}$ The two new absorbance peaks suggested that amine groups of PEI interacted with acyl chloride groups of IPC and TMC at interface and produced the amide bond. The intensity of absorbance peak at $3400 \mathrm{~cm}^{-1}$ became weaker with an increase in the mass ratio of IPC to TMC. On the other hand, two new weak absorbance peaks at $1610 \mathrm{~cm}^{-1}$ and $1550 \mathrm{~cm}^{-1}$ arose as well, and the intensity of absorbance peak at $3043 \mathrm{~cm}^{-1}$ increased. These results suggested that the PA/PS composite NF membrane should contain the aromatic rings as introduced by acyl chloride molecules. The new weak absorbance peaks at $1610 \mathrm{~cm}^{-1}$ and $1550 \mathrm{~cm}^{-1}$ could be attributed to the $\mathrm{C}=\mathrm{C}$ stretching peaks of TMC and IPC. ${ }^{46,47}$

3.1.4. Hydrophilicity of the membrane surface. Hydrophilicity of membrane surface was known to influence the permeate flux. Generally, the more hydrophilic the membrane surface is, the higher the permeate flux is. The contact angles of the PSF UF substrate and the PA/PSF composite NF membranes were displayed in Table 2 . The contact angle of the commercial PSF UF substrate was $75.1 \pm 0.6^{\circ} .^{48}$ Once IP introduced hydrophilic groups to membrane surface and promoted surface roughness, the contact angles of the $\mathrm{PA}_{01} / \mathrm{PSF}, \mathrm{PA}_{11} / \mathrm{PSF}$, and $\mathrm{PA}_{10} / \mathrm{PSF}$ composite NF membranes reduced to $53.7 \pm 0.7^{\circ}, 44.7$ $\pm 0.2^{\circ}$, and $51.6 \pm 0.4^{\circ}$, respectively. Obviously, contact angle was strongly affected by the surface roughness and the density of the amine groups on PEI. Although many amine groups on the surface of PA10/PSF composite NF membrane were dissociative, the difference in the amount of amine groups of three tested membranes was tiny. Thus, the roughness might be the main factor to determine the contact angle. According to the AFM data, the $\mathrm{PA}_{11} / \mathrm{PSF}$ have the largest roughness. Therefore, the $\mathrm{PA}_{11} / \mathrm{PSF}$ composite NF membranes was hydrophilic and could be wetted easily. ${ }^{51-55}$

3.1.5. Electrokinetic property of membrane surface. The electrokinetic property of the membrane surface was investigated by zeta potential. Fig. 6 showed the zeta potentials on the surfaces of the PSF UF substrate, $\mathrm{PA}_{01} / \mathrm{PSF}, \mathrm{PA}_{11} / \mathrm{PSF}$, and $\mathrm{PA}_{10} /$ PSF composite NF membranes at different pHs. In Fig. 6(a), PSF UF substrate was negatively charged at $\mathrm{pH}$ above IEP of 3.08, suggesting that it was negatively charged at $\mathrm{pH}$ above 3.08. As seen in Fig. 6(b-d), the isoelectric points (IEP) of the $\mathrm{PA}_{01} / \mathrm{PSF}$, $\mathrm{PA}_{11} / \mathrm{PSF}$, and $\mathrm{PA}_{10} / \mathrm{PSF}$ composite NF membranes were 9.73, 9.81, and $9.85,{ }^{36,39,40,47,56,57}$ respectively, similar to the results by Sun, et al. ${ }^{58}$ Evidently, the resultant PA/PSF composite NF 

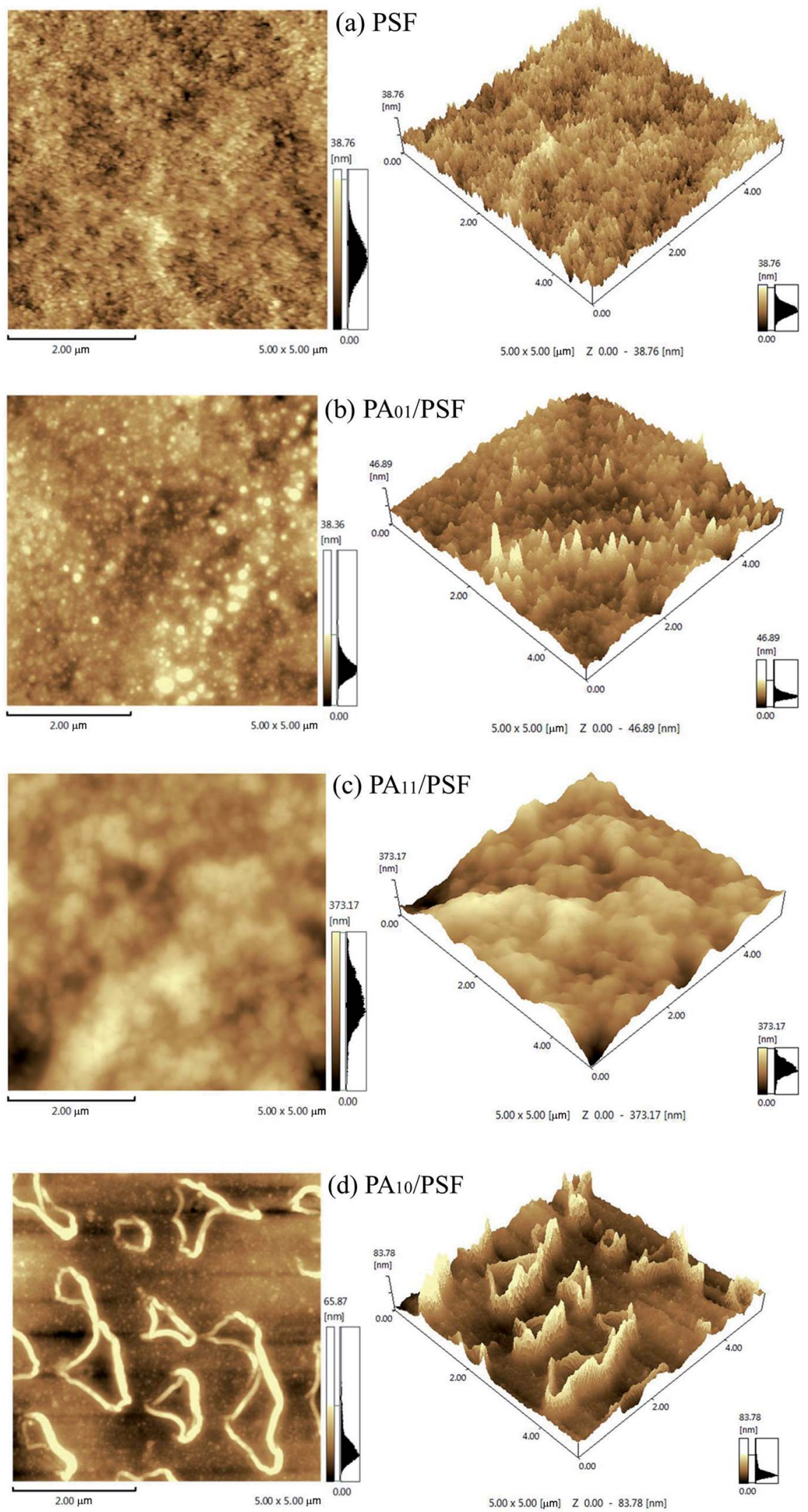

Fig. 4 The 2-D and 3-D surface morphologies of (a) PSF UF substrate, (b) PA $A_{01} / P S F$, (c) $P A_{11} / P S F$ and (d) $P A_{10} / P S F$ positively charged composite NF membranes in an area of $5 \mu \mathrm{m} \times 5 \mu \mathrm{m}$. 


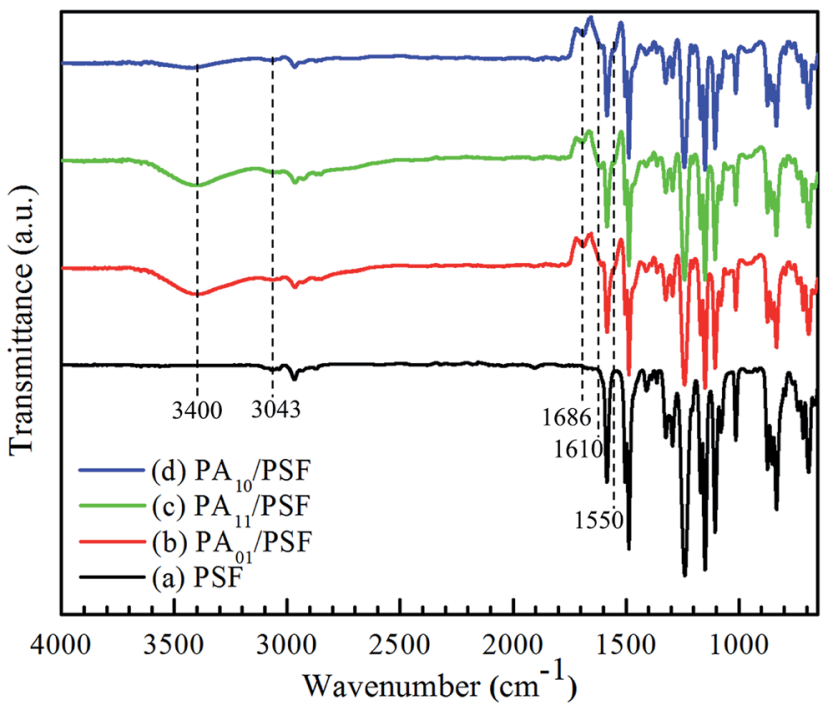

Fig. 5 ATR-IR spectra of (a) PSF UF substrate, positively charged (b) $\mathrm{PA}_{01} / \mathrm{PSF}$, (c) $\mathrm{PA}_{11} / \mathrm{PSF}$, and (d) $\mathrm{PA}_{10} / \mathrm{PSF}$ composite NF membranes.

Table 2 Contact angle of the PSF UF substrate and the positively charged PA/PSF composite NF membrane

\begin{tabular}{ll}
\hline Membrane & Contact angle $\left(^{\circ}\right)$ \\
\hline $\mathrm{PSF}$ & $75.1 \pm 0.6$ \\
$\mathrm{PA}_{01} / \mathrm{PSF}$ & $53.7 \pm 0.7$ \\
$\mathrm{PA}_{11} / \mathrm{PSF}$ & $44.7 \pm 0.2$ \\
$\mathrm{PA}_{10} / \mathrm{PSF}$ & $51.6 \pm 0.4$
\end{tabular}

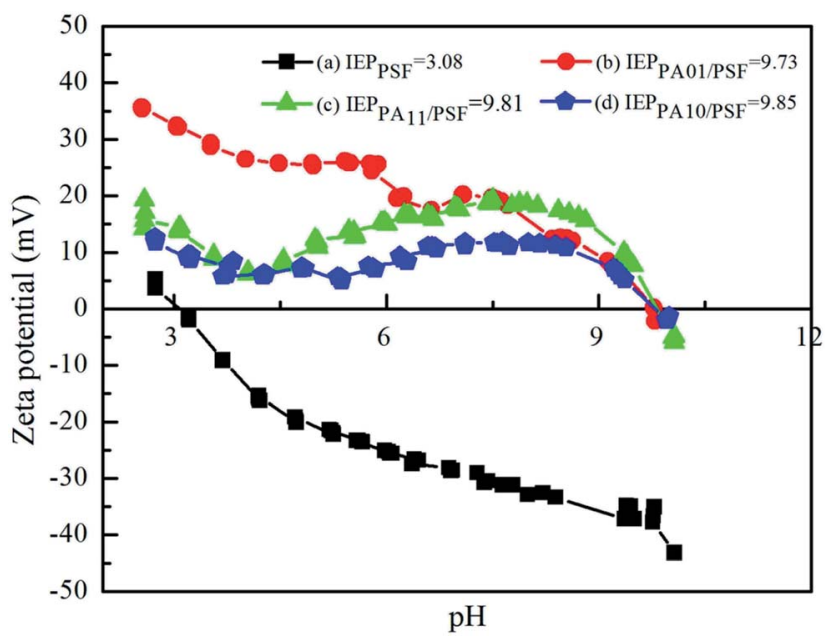

Fig. 6 Zeta potentials of (a) PSF UF substrate, (b) PA $A_{01} / P S F$, (c) $\mathrm{PA}_{11} / \mathrm{PSF}$ and (d) $\mathrm{PA}_{10}$ /PSF composite NF membranes.

membranes based on PEI were positively charged. The IEP of the resultant PA/PSF composite NF membranes increased with the increase in the mass ratio of IPC to TMC.

The surface charge fluctuated below $\mathrm{pH} 7$, probably due to the unstable polyamide-based membrane at extreme $\mathrm{pH}$.
Especially, the polyamide membranes prepared with IPC as the organic monomer were less stable than those made with TMC, because its' $\mathrm{C}-\mathrm{N}$ bond would be much more easily attacked by the $\mathrm{H}^{+}$without the protection of the steric hindrance effect, and the lonely-pair electrons on the $\mathrm{N}$ atom would be captured by $\mathrm{H}^{+}$ to form $\mathrm{N}-\mathrm{H}$ bond. Then a portion of amide groups would be destroyed to produce dissociative amido and carboxyl groups via hydrolysis, resulting the fluctuation of the surface charge below $\mathrm{pH} 7 .^{47}$

3.1.6. MWCO of the resultant PA/PSF composite NF membrane. Herein, the PEG aqueous solutions of MWs in the range of 400 to 2000 Da were employed to determine the MWCO of the $\mathrm{PA}_{01} / \mathrm{PSF}, \mathrm{PA}_{11} / \mathrm{PSF}$, and $\mathrm{PA}_{10} / \mathrm{PSF}$ composite $\mathrm{NF}$ membranes. ${ }^{59}$ Fig. 7 showed the rejections of the resultant composite NF membranes to PEG of different MWs. The MWCO of $\mathrm{PA}_{01} / \mathrm{PSF}, \mathrm{PA}_{11} / \mathrm{PSF}$, and $\mathrm{PA}_{10} / \mathrm{PSF}$ composite NF membranes were determined to be 676,722 , and $684 \mathrm{Da}$, respectively. The membrane pore size could be obtained from the correlation equation to convert MWCO to pore size. ${ }^{60}$

\subsection{Effect of mass ratio of IPC to TMC on the rejection performance of the PA/PSF composite NF membrane}

Fig. 8 shows the effect of mass ratio of IPC to TMC on the rejection performance of the PA/PSF composite NF membrane. The rejection to $\mathrm{MgCl}_{2}$ increased from $94.5 \%$ to $97.8 \%$ with mass ratio of IPC to TMC, while the permeate flux of PA/PSF composite NF membrane grew gradually with mass ratio of IPC to TMC till it reached $1: 1$ and lowered at higher mass ratio of IPC to TMC. The maximum permeate flux was $24.7 \mathrm{~L} \mathrm{~m}^{-2} \mathrm{~h}^{-1}$ at $1: 1$ mass ratio of IPC to TMC. The chemical structure of the active layer changed with mass ratio of IPC and TMC, resulting in the variation of rejection performance of PA/PSF composite NF membrane. Thus, a positively charged PA/PSF composite NF membrane with tunable active layer could be developed by adjusting the mass ratio of IPC and TMS in the organic phase.

\subsection{Rejection performance of the positively charged $\mathbf{P A}_{\mathbf{1 1}} /$ PSF composite NF membrane}

3.3.1. Rejection performance to inorganic electrolytes. The rejection performance of the positively charged $\mathrm{PA}_{11} / \mathrm{PSF}$ composite NF membrane to different inorganic electrolytes was evaluated in this section. Fig. 9 showed the rejection performance to different inorganic electrolytes, including $\mathrm{CaCl}_{2}$, $\mathrm{CuCl}_{2}, \mathrm{MgCl}_{2}, \mathrm{ZnCl}_{2}, \mathrm{MgSO}_{4}, \mathrm{NaCl}$ and $\mathrm{Na}_{2} \mathrm{SO}_{4}$. The permeate flux was approximate $25.0 \mathrm{~L} \mathrm{~m}^{-2} \mathrm{~h}^{-1}$ in each case and the rejection of the positively charged $\mathrm{PA}_{11} / \mathrm{PSF}$ composite $\mathrm{NF}$ membrane followed the order of $\mathrm{ZnCl}_{2}(97.7 \%)>\mathrm{MgCl}_{2}(97 \%)>$ $\mathrm{CuCl}_{2}(96.9 \%)>\mathrm{CaCl}_{2}(95.3 \%)>\mathrm{MgSO}_{4}(88.3 \%)>\mathrm{NaCl}(74.2 \%)$ $>\mathrm{Na}_{2} \mathrm{SO}_{4}(47.8 \%)$. According to Donnan exclusion principle, the rejection of the positively charged NF membranes to divalent cations $\left(\mathrm{Zn}^{2+}, \mathrm{Mg}^{2+}, \mathrm{Cu}^{2+}\right.$, and $\left.\mathrm{Ca}^{2+}\right)$ was expected higher than that to monovalent cation $\left(\mathrm{Na}^{+}\right)$, and the rejection to cation should be higher than that to anion. ${ }^{61}$ On the other hand, the hydrate radii of various ions were in order of $\mathrm{Zn}^{2+}>\mathrm{Mg}^{2+}>\mathrm{Cu}^{2+}$ $>\mathrm{Ca}^{2+}>\mathrm{SO}_{4}{ }^{2-}>\mathrm{Na}^{+}>\mathrm{Cl}^{-}$as a result of the steric-hindrance effect. $^{\mathbf{4 3 , 6 2 , 6 3}}$ The above results suggested that the rejection 

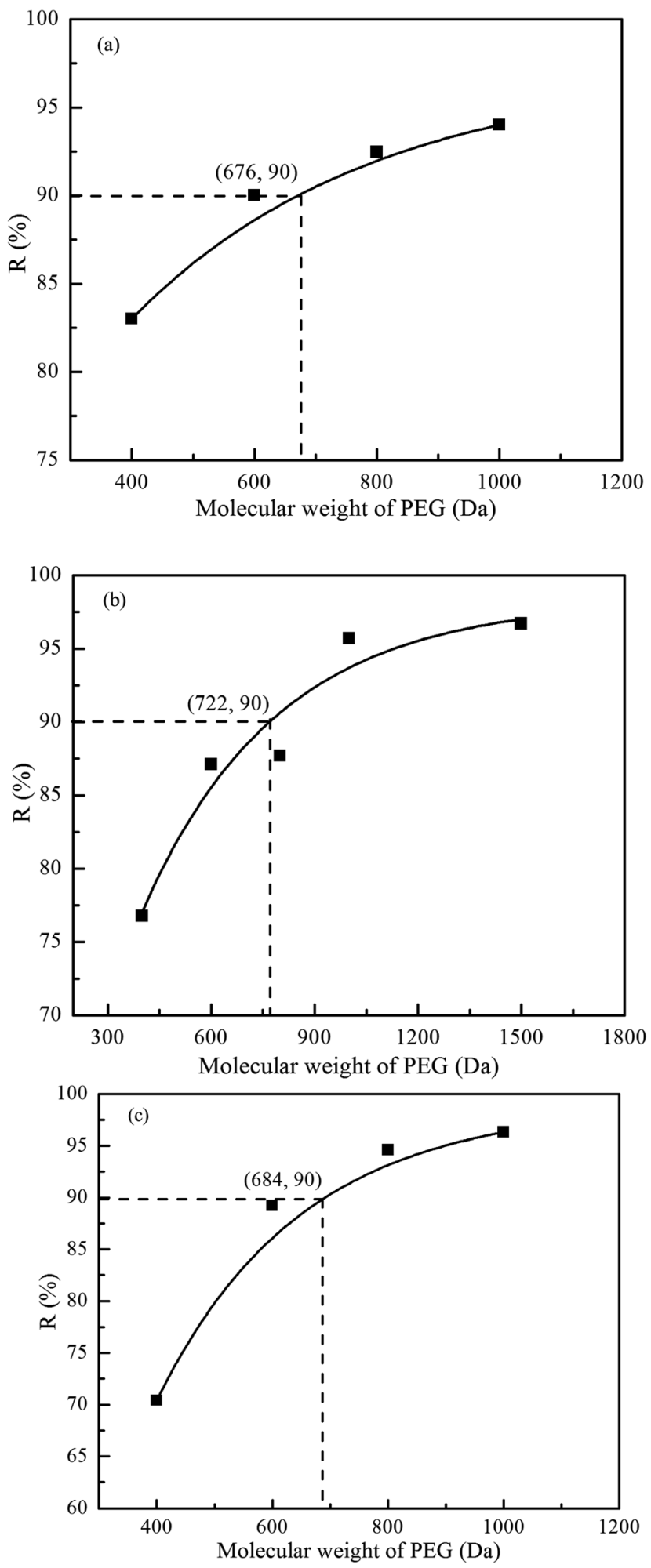

Fig. 7 Rejections PEG rejection rates of different molecular weight for the (a) $\mathrm{PA}_{01} / \mathrm{PSF}$, (b) $\mathrm{PA}_{11} / \mathrm{PSF}$ and (c) $\mathrm{PA}_{10} / \mathrm{PSF}$ positively charged composite NF membranes.

performance of the $\mathrm{PA}_{11} / \mathrm{PSF}$ composite $\mathrm{NF}$ membrane were mainly determined by Donnan exclusion effect and sterichindrance effect.

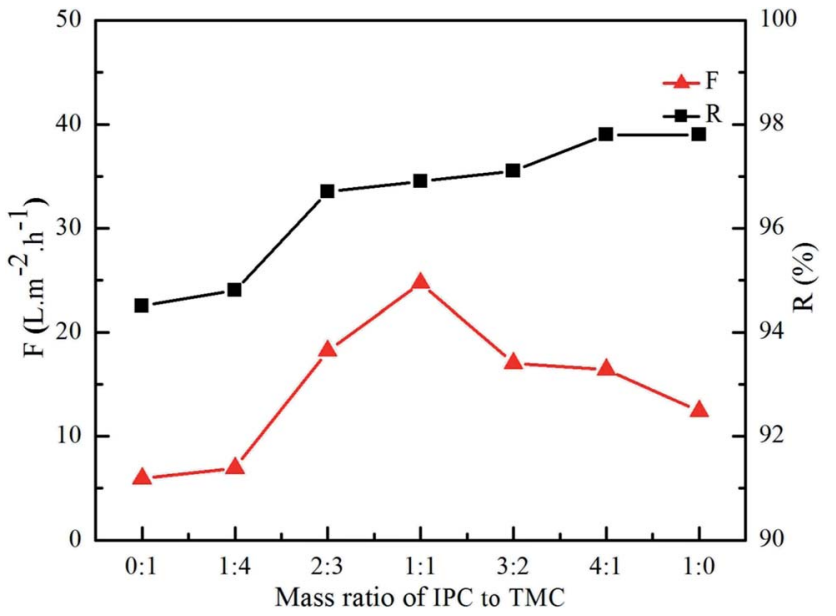

Fig. 8 Effect of mass ratio of IPC to TMC on separation performance of positively charged PA/PSF composite NF membranes.

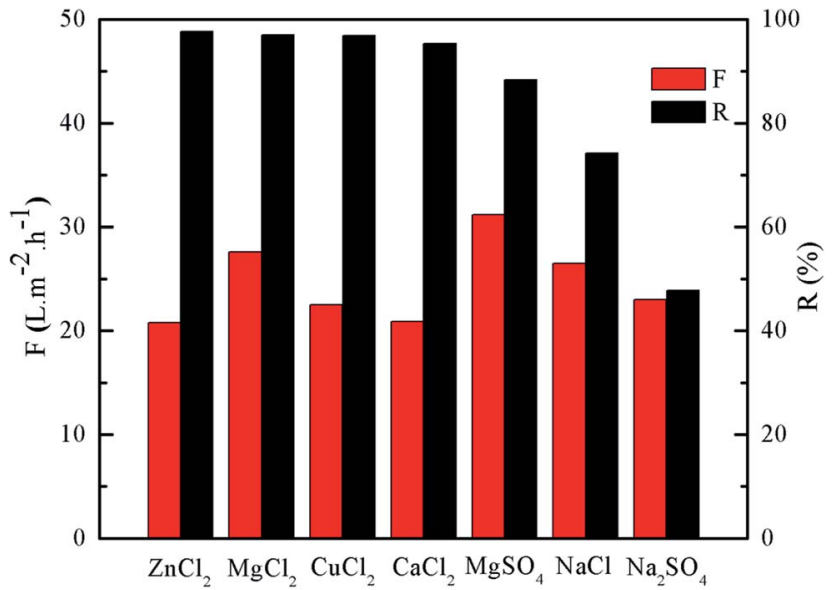

Fig. 9 Rejection performance of the $\mathrm{PA}_{11} / \mathrm{PSF}$ composite NF membrane to different inorganic electrolytes.

3.3.2. Rejection to dyes of different MWs and charges. Table 3 shows the rejection performance of the positively charged $\mathrm{PA}_{11} / \mathrm{PSF}$ composite $\mathrm{NF}$ membrane to dyes with different MW and charge. Four dyes were employed in this study and they included three cationic dyes (cationic red X-GTL, rhodamine B, and cationic gold yellow X-GL), and one anionic dye (reactive brilliant blue KN-R). Rejection to the four dyes followed the sequence of cationic red X-GTL $(100.0 \%)>$ rhodamine B $(94.2 \%)>$ cationic gold yellow X-GL $(93.5 \%)>$ reactive brilliant blue KN-R (43.9\%).

Among the three cationic dyes, the rejection to divalent cationic red X-GTL was the highest, while the rejections to the monovalent positively charged rhodamine $\mathrm{B}$ and cationic gold yellow X-GL were lower and the difference in the rejections of the two dyes were negligible. However, the negatively charged dye with the highest $M_{\mathrm{w}}$, reactive brilliant blue KN-R exhibited the lowest rejection among the four dyes, suggesting that the charge of the dye (anionic $v s$. cationic) had huge impact on the rejection of the $\mathrm{PA}_{11} / \mathrm{PSF}$. Both Donnan exclusion effect and 
Table 3 Rejection performance of the $\mathrm{PA}_{11} / \mathrm{PSF}$ composite NF membrane to dyes with different MW and charge

\begin{tabular}{|c|c|c|c|c|}
\hline Dye & $M_{\mathrm{w}}(\mathrm{Da})$ & $\begin{array}{l}\text { Maximum absorption } \\
\text { wavelength }(\mathrm{nm})\end{array}$ & $R(\%)$ & $F\left(\mathrm{~L} \mathrm{~m}^{-2} \mathrm{~h}^{-1}\right)$ \\
\hline Brilliant blue KN-R & 626.5 & 592 & 43.9 & 18.6 \\
\hline Cationic red X-GTL & 502.0 & 530 & 100.0 & 14.9 \\
\hline Rhodamine B & 479.0 & 560 & 94.2 & 13.9 \\
\hline Cationic gold yellow X-GL & 433.5 & 441 & 93.5 & 19.6 \\
\hline
\end{tabular}

steric-hindrance effect played key roles in the rejection to dyes with different $M_{\mathrm{w}}$ and charge. . $^{61,62}$

\section{Conclusions}

In this work, a novel positively charged composite NF membrane with tunable active layer structures was prepared by adjusting the mass ratio of IPC to TMC in the organic phase via interfacial polymerization. The characterizations with SEM, AFM, ATR-FTIR, contact angle, and zeta potential measurement confirmed the successful fabrication of the desirable membranes with hydrophilic nature and revealed the microscopic morphologies of wrinkles or twisted particles at membrane surface.

Synergetic effect was found in a mixture of IPC and TMC as the active layer. The resultant PA/PSF membranes not only had relatively thinner active layers, but also were more permeable than the membranes developed with TMC or IPC alone. Additionally, the optimized resultant positively charged PA/PSF composite NF membrane showed excellent rejection performance to cationic dyes and inorganic electrolytes of divalent cations. In summary, the structure of the active layer could be tuned by regulating the mass ratio of two monomers in organic phase, which in turn was closely related to permeate flux.

The results will provide rich information to establish a foundation for the development of PEI TFC positively charged $\mathrm{PA}$ composite NF membranes bearing great $R$ and $F$ performance.

\section{Conflicts of interest}

There are no conflicts of interest to declare.

\section{Abbreviation}

$\begin{array}{ll}\text { AFM } & \text { Atomic force microscopy } \\ \text { ATR-FTIR } & \text { Attenuated total reflectance-Fourier } \\ \text { spectroscopy } & \text { transform infrared spectroscopy } \\ \text { CA } & \text { Contact angle } \\ \text { Dex } & \text { Dextran } \\ \text { IP } & \text { Interfacial polymerization } \\ \text { IPC } & \text { Isophthaloyl dichloride } \\ M_{\mathrm{w}} & \text { Molecular weight } \\ \text { MWCO } & \text { Molecular weight cut-off } \\ \text { NF } & \text { Nanofiltration membrane } \\ F & \text { Permeate flux } \\ \text { PSF } & \text { Polysulfone }\end{array}$

$\begin{array}{ll}\text { PEI } & \text { Polyethyleneimine } \\ \text { PEG } & \text { Polyethylene glycol } \\ \text { PA } & \text { Polyamide } \\ R & \text { Rejection } \\ \text { RO } & \text { Reverse osmosis } \\ R_{\text {rms }} & \text { Root mean square roughness } \\ \text { SEM } & \text { Scanning electron microscopy } \\ \text { TMC } & \text { Tri-mesoyl chloride } \\ \text { UF } & \text { Ultrafiltration }\end{array}$

\section{Acknowledgements}

The authors are grateful for the support for the Project on the Integration of Industry, Education and Research of Guangdong Province (2016B090918048), and the International Science \& Technology Cooperation Program of Nansha Free Trade Zone (2015GJ002), and the Two-Hundred Talents of Yantai City, Shandong Province, China.

\section{References}

1 Y. F. Song, J. Xu, Y. Xu, X. L. Gao and C. J. Gao, Desalination, 2011, 276, 109-116.

2 A. M. Hassan, M. A. K. Al-Sofi, A. S. Al-Amoudi, A. T. M. Jamaluddin, A. M. Farooque, A. Rowaili, A. G. I. Dalvi, N. M. Kither, G. M. Mustafa and I. A. R. AlTisan, Desalination, 1998, 118, 35-51.

3 A. M. Hassan, A. M. Farooque, A. T. M. Jamaluddin, A. S. AlAmoudi, M. A. Al-Sofi, A. F. Al-Rubaian, N. M. Kither, I. A. R. Al-Tisan and A. Rowaili, Desalination, 2000, 131, 157-171.

4 N. Fridman-Bishop, O. Nir, O. Lahav and V. Freger, Environ. Sci. Technol., 2015, 49, 8631-8638.

5 E. Zuriaga-Agusti, M. I. Iborra-Clar, J. A. Mendoza-Roca, M. Tancredi, M. I. Alcaina-Miranda and A. Iborra-Clar, Chem. Eng. J., 2010, 161, 122-128.

6 R. Othman, A. W. Mohammad, M. Ismail and J. Salimon, J. Membr. Sci., 2010, 348, 287-297.

7 B. Tepus, M. Simonic and I. Petrinic, J. Hazard. Mater., 2009, 170, 1210-1217.

8 V. Yangali-Quintanilla, S. K. Maeng, T. Fujioka, M. Kennedy and G. Amy, J. Membr. Sci., 2010, 362, 334-345.

9 S. Kaur, R. Barhate, S. Sundarrajan, T. Matsuura and S. Ramakrishna, Desalination, 2011, 279, 201-209.

10 L. Xing, N. Guo, Y. Zhang, H. Zhang and J. Liu, Sep. Purif. Technol., 2015, 146, 50-59. 
11 J. Y. Zhu, N. N. Guo, Y. T. Zhang, L. Yu and J. D. Liu, J. Membr. Sci., 2014, 465, 91-99.

12 A. K. An, J. Guo, S. Jeong, E. J. Lee, S. A. A. Tabatabai and T. Leiknes, Water Res., 2016, 103, 362-371.

13 A. Tiraferri and M. Elimelech, J. Membr. Sci., 2012, 389, 499508.

14 X. Li, T. Cai, C. Chen and T. S. Chung, Water Res., 2016, 89, 50-58.

15 X. Wei, X. Bao, J. Wu, C. Li, Y. Shi, J. Chen, B. Lv and B. Zhu, RSC Adv., 2018, 8, 10396-10408.

16 P. B. Kosaraju and K. K. Sirkar, J. Membr. Sci., 2008, 321, 155161.

17 Y. J. Song, P. Sun, L. L. Henry and B. H. Sun, J. Membr. Sci., 2005, 251, 67-79.

18 A. P. Rao, S. V. Joshi, J. J. Trivedi, C. V. Devmurari and V. J. Shah, J. Membr. Sci., 2003, 211, 13-24.

19 I. J. Roh, J. Membr. Sci., 2002, 198, 63-74.

20 Y. Mansourpanah, S. S. Madaeni and A. Rahimpour, J. Membr. Sci., 2009, 343, 219-228.

21 B. B. Tang, C. Zou and P. Y. Wu, J. Membr. Sci., 2010, 365, 276-285.

22 H. Q. Wu, B. B. Tang and P. Y. Wu, J. Phys. Chem. C, 2010, 114, 16395-16400.

23 B. J. Abu Tarboush, D. Rana, T. Matsuura, H. A. Arafat and R. M. Narbaitz, J. Membr. Sci., 2008, 325, 166-175.

24 J. Jegal, S. G. Min and K. H. Lee, J. Appl. Polym. Sci., 2002, 86, 2781-2787.

25 A. L. Ahmad, B. S. Ooi, A. W. Mohammad and J. P. Choudhury, Ind. Eng. Chem. Res., 2004, 43, 8074-8082.

26 A. K. Ghosh, B. H. Jeong, X. F. Huang and E. M. V. Hoek, J. Membr. Sci., 2008, 311, 34-45.

27 Y. C. Chiang, Y. Z. Hsub, R. C. Ruaan, C. J. Chuang and K. L. Tung, J. Membr. Sci., 2009, 326, 19-26.

28 S. P. Sun, T. A. Hatton, S. Y. Chan and T. S. Chung, J. Membr. Sci., 2012, 401, 152-162.

29 Z. W. Thong, Y. Cui, Y. K. Ong and T. S. Chung, ACS Sustainable Chem. Eng., 2016, 4, 5570-5577.

30 J. Gao, S. P. Sun, W. P. Zhu and T. S. Chung, J. Membr. Sci., 2016, 499, 361-369.

31 K. P. Lee, J. M. Zheng, G. Bargeman, A. J. B. Kemperman and N. E. Benes, J. Membr. Sci., 2015, 478, 75-84.

32 A. Bera, J. S. Trivedi, S. K. Jewrajka and P. K. Ghosh, J. Membr. Sci., 2016, 519, 64-76.

33 D. H. Wu, S. C. Yu, D. Lawless and X. S. Feng, React. Funct. Polym., 2015, 86, 168-183.

34 W. Fang, L. Shi and R. Wang, J. Membr. Sci., 2014, 468, 52-61. 35 X. Wei, S. Wang, Y. Shi, H. Xiang, J. Chen and B. Zhu, Desalination, 2014, 350, 44-52.

36 X. Wei, S. Wang, Y. Shi, H. Xiang, J. Chen and B. Zhu, Desalination, 2014, 350, 44-52.

37 A. E. Childress and M. Elimelech, J. Membr. Sci., 1996, 119, 253-268.
38 A. Bera, J. S. Trivedi, S. K. Jewrajka and P. K. Ghosh, J. Membr. Sci., 2016, 519, 64-76.

39 D. Wu, Y. Huang, S. Yu, D. Lawless and X. Feng, J. Membr. Sci., 2014, 472, 141-153.

40 D. Wu, S. Yu, D. Lawless and X. Feng, React. Funct. Polym., 2015, 86, 168-183.

41 P. S. Shi, T. A. Hatton, Y. C. Sui and T. S. Chung, J. Membr. Sci., 2012, 401, 152-162.

42 Z. W. Thong, Y. Cui, Y. K. Ong and T. S. Chung, ACS Sustainable Chem. Eng., 2016, 4, 5570-5577.

43 W. Fang, L. Shi and R. Wang, J. Membr. Sci., 2013, 430, 129139.

44 W.-S. Hung, Y.-H. Chiao, A. Sengupta, Y.-W. Lin, S. R. Wickramasinghe, C.-C. Hu, H.-A. Tsai, K.-R. Lee and J.-Y. Lai, Carbon, 2019, 142, 337-345.

45 M. Hirose, H. Ito and Y. Kamiyama, J. Membr. Sci., 1996, 121, 209-215.

46 D. Wu, J. Martin, J. R. Du, Y. Zhang, D. Lawless and X. Feng, J. Membr. Sci., 2015, 487, 256-270.

47 K. P. Lee, J. Zheng, G. Bargeman, A. J. B. Kemperman and N. E. Benes, J. Membr. Sci., 2015, 478, 75-84.

48 F. Y. Zhao, Y. L. Ji, X. D. Weng, Y. F. Mi, C. C. Ye, Q. F. An and C. J. Gao, ACS Appl. Mater. Interfaces, 2016, 8, 6693-6700.

49 W. Fang, L. Shi and R. Wang, J. Membr. Sci., 2014, 468, 52-61.

50 F. Y. Zhao, Q. F. An, Y. L. Ji and C. J. Gao, J. Membr. Sci., 2015, 492, 412-421.

51 K. Vanherck, A. Cano-Odena, G. Koeckelberghs, T. Dedroog and I. Vankelecom, J. Membr. Sci., 2010, 353, 135-143.

52 Y. Si and Z. Guo, Nanoscale, 2015, 7, 5922.

53 L. Jiang, Z. Tang, R. M. Clinton, V. Breedveld and D. W. Hess, ACS Appl. Mater. Interfaces, 2017, 9, 9195-9203.

54 S. Song, H. Yang, C. Su, Z. Jiang and Z. Lu, Chem. Eng. J., 2016, 306, 504-511.

55 H. Yang, P. Pi, Z. R. Yang, Z. Lu and R. Chen, Appl. Surf. Sci., 2016, 388, 268-273.

56 M. Dalwani, N. E. Benes, G. Bargeman, D. Stamatialis and M. Wessling, J. Membr. Sci., 2010, 363, 188-194.

57 C. Feng, J. Xu, M. Li, Y. Tang and C. Gao, J. Membr. Sci., 2014, 451, 103-110.

58 S. P. Sun, T. A. Hatton, S. Y. Chan and T.-S. Chung, J. Membr. Sci., 2012, 401-402, 152-162.

59 X. Wei, S. Wang, Y. Shi, H. Xiang and J. Chen, Ind. Eng. Chem. Res., 2013, 53, 14036-14045.

60 M. D. Afonso, G. Hagmeyer and R. Gimbel, Sep. Purif. Technol., 2001, 22-23, 529-541.

61 A. H. Galama, J. W. Post, M. A. C. Stuart and P. M. Biesheuvel, J. Membr. Sci., 2013, 442, 131-139.

62 J. Heo, L. K. Boateng, J. R. V. Flora, H. Lee, N. Her, Y. G. Park and Y. Yoon, J. Membr. Sci., 2013, 443, 69-82.

63 E. R. J. Nightingale, J. Phys. Chem. C, 1958, 63, 566-567. 